\title{
Are Minority Serving Institutions Contributing to Unhealthy Eating and Health Disparities Among College Students: A Pilot Study
}

\author{
Jannat Begum $^{1} \&$ Naa-Solo Tettey ${ }^{1}$ \\ ${ }^{1}$ Department of Public Health, William Paterson University, Wayne, NJ, USA \\ Correspondence: Naa-Solo Tettey, Department of Public Health, William Paterson University, Wayne, NJ 07470, \\ USA. E-mail: tetteyn@wpunj.edu
}

Received: August 16, 2019

Accepted: September 26, 2019

Online Published: February 17, 2020

doi:10.5539/ies.v13n3p1

URL: https://doi.org/10.5539/ies.v13n3p1

\begin{abstract}
Dietary habits are developed through a combination of biological, environmental, socioeconomic, and psychosocial factors. However, these dietary habits can also be influenced by access and education. College undergraduate years are important for the development of life skills including the ability to select nutritious meals. This is of vital importance for students who are from communities that are classified as food desserts and food swamps, where positive nutrition behaviors may not be supported. The purpose of this pilot study was to assess the food options at two minority serving institutions in New Jersey to determine the amount of healthy options available. A content analysis was completed by assessing the menus of the selected dining services at the respective institutions and determining their health impact. Twenty-seven food establishments were analyzed. The food locations were categorized into healthy dining (7.4\%), unhealthy dining $(14.8 \%)$, healthy fast food (7.4\%), unhealthy fast food $(40.7 \%)$, healthy café $(3.7 \%)$, unhealthy café $(18.5 \%)$, healthy prepackaged $(0 \%)$, and unhealthy prepackaged (7.4\%). Healthy eateries made up $18.5 \%$ and unhealthy eateries made up $81.4 \%$ of the food offerings. This significant difference in healthy compared to unhealthy offerings is a call to action to improve food choices on the campuses of minority serving institutions. Chronic diseases continue to impact people of younger ages and contribute to health disparities. Colleges have a unique opportunity to positively influence the lifestyle behaviors that can decrease these chronic disease rates. Future studies should investigate the food options at minority serving institutions throughout the United States.
\end{abstract}

Keywords: health disparities, nutrition, minority serving institutions, college

\section{Introduction}

Chronic diseases such as diabetes, hypertension, and cardiovascular disease continue to increase worldwide and have created various public health challenges. Many chronic diseases are negatively impacted by poor lifestyle choices and can be prevented through improvements in diet, exercise, and other health behaviors. Heart disease, diabetes, obesity, and hypertension, impact African American and Hispanic communities at higher rates and contribute to increased morbidity and mortality within these groups (Centers for Disease Control and Prevention [CDC], 2014a). Diabetes rates are 77\% higher in non-Hispanic blacks, $66 \%$ higher in Hispanics, and $18 \%$ higher in Asians than the rates as seen in non-Hispanic whites. In addition, compared to whites, non-Hispanic blacks are $40 \%$ more likely to have high blood pressure (CDC, 2014a). The health disparities in these rates of chronic diseases are due in part to income level, education status, access to health care, and the conditions of one's community (Graham, 2015). Children are disproportionately affected by ethnic and racial health disparities and have four times the chance of acquiring a chronic disease if they fall under the bracket of racial or ethnic minority (Price, et al., 2013). Due to the various inequities that are faced by poor and minority communities, prevention has been challenging (Kumanyika, 2018). As a result, in addition to being considered a public health problem, chronic disease is also a social justice issue. Lack of access to nutritious food, low health literacy, and obesity are major contributing factors (Hossain, Kawar, \& Nahas, 2007; CDC, 2014b). College campuses may be a point of intervention that has not been completely explored.

Poor dietary habits among college students in the United States are an area that has been studied. However, there has not been an explicit focus on minority serving institutions and the impact of their food offerings on students. This distinction is important since it has already been demonstrated that unhealthy eating behaviors for students on college campuses can lead to an increase in body weight, obesity, and chronic diseases (Morrell, Lofgren, Burke, 
\& Reilly, 2012). Furthermore, the food environment is highly influential in establishing dietary practices (Giskes, van Lenthe, Avendano-Pabon, \& Brug, 2011). Food deserts and food swamps are communities with minimal or no access to healthy affordable food such as fruits, vegetables, low-fat milk, whole grains, and other supplements that contribute to a balanced diet (Cooksey-Stowers, Schwartz, \& Brownell, 2017). Low income and ethnic minority neighborhoods are more likely to be categorized as food deserts and have higher levels of food insecurity. Foods swamps, in comparison, also result in health disparities and are areas with a disproportionate amount of high-calorie fast food and junk food with few, and often overpriced, options for healthy alternatives (Cooksey-Stowers, Schwartz, \& Brownell, 2017). Research has shown that the presence of fast food outlets is much greater in ethnic minority communities compared to White communities (Fleischhacker, Evenson, Rodriguez, \& Ammerman, 2011). The phenomena of food deserts and food swamps can be exacerbated on college campuses, especially Hispanic-serving institutions (HSIs), universities with Latino enrollments of $25 \%$ or more full-time students (Laden, 2010), and minority-serving institutions (MSIs), or institutions serving at least one-third of all African American, Hispanic, and American Indian students enrolled in higher education (Merisotis \& McCarthy, 2005).

With health disparities among racial and ethnic minorities continuing to increase in the United States, college campuses can serve as a catalyst for developing healthy lifestyle behaviors in students from these backgrounds (Kapinos \& Yakusheva, 2011). However, this cannot occur if the food environment at minority serving institutions is unhealthy. The purpose of this pilot study is to assess the food offerings at two minority serving institutions to determine the health quality of the items being sold.

\section{Method}

Food establishments at two universities in New Jersey were assessed. Both schools are classified as Hispanic serving institutions and fall under the broader category of minority serving institutions. These schools were also selected due to the proximity and accessibility for the researchers. Only food offerings not provided by the formal university dining hall were assessed. The reasoning for this is that dining hall options are only available to students who have a meal plan or live on campus.

The dining establishments at institution one that met the inclusion criteria were Billy Bear Grill, The Wingery, Einstein, Mein Bowl, Pioneer Pizzeria, Campus Store, Starbucks, Dining Hall, Simply To Go, and Hissho Sushi. The eateries at institution two are Au Bon Pain, Bistro 62, Blanton CStore, California Tortilla, Chilis, Dunkin Donuts Student Center Patio, Dunkin Donuts, Freeman Dining Hall, Grill Nation, Olo Sushi, Panda Express, Rathskeller 2Mato Chop'd, Red Hawk Diner, Red Hawk Express Food Truck, Sam's Place, Shawarma Spot Food Truck, So Deli Student Center Patio, Student Center CStore, Student Center Dining Room, The Rift Zone, University Hall Cafe, Venture Cafe, and Which Wich. In total, 10 eating locations were analyzed at institution one, and 17 of the 20 named above were assessed at institution two. Food establishments were omitted from the study if nutritional information was not available.

A content analysis was completed by assessing the menus of the selected dining services at the respective institutions and determining their health impact, based on category and a healthy or unhealthy determination derived from a system established by Carlson and Frazao (2012). The categories used for analysis were: dining (sit down, full table service, self-service), fast food (minimal service, quick preparation, food cooked in bulk and reheated), café (primarily non-entrée items, coffee, pastries, yogurt, smoothies), and prepackaged (processed snacks, prepackaged and paid for at counter). Four college student research assistants completed the assessments at each school. All students were trained in the assessment tool and interrater reliability (IRR) was established by having the research assistants each independently assess the same store at each institution on the same day.

Carlson and Frazao's (2012) definition of food groups was used to determine if the food offerings were healthy or unhealthy. Particularly for fruits, vegetables, and sources of animal protein, Carlson and Frazao (2012) provided portion sizes and minimal cutoffs to gauge the nutritional content of the foods sold at the respective institutions. These measures were used as a baseline from which to assess the average serving size for items used for analysis in the study. In addition, the Nutritional Environment Measures Survey (NEMS) for restaurants, corner stores, and grab-and-go facilities provided the guidelines for deciding the healthiness of an eatery (Glanz, Sallis, Saelens, \& Frank, 2007). This categorization was based on nutrition labeling or information provided through packaging or other means such as a sign. For restaurant and fast food eateries, the NEMS-R survey was used and each location was examined for the availability of healthful options (fruit, non-fried vegetables, main dish salads, etc.), facilitators of healthy eating (such as nutritional information and the encouragement of healthy requests), and barriers to healthful eating (low-carbohydrate promotion, combination meals made cheaper, etc.) (Saelens, Glanz, Sallis, \& Frank, 2007). The availability of whole fruits and vegetables at different eateries, particularly for 
grab-and-go locations, was another factor used to assess healthy food options (Cavanaugh, Mallya, Brensinger, Tierney, \& Glanz, 2013).

\section{Results}

Twenty-seven eating locations were analyzed in total on both campuses. A percentage frequency distribution was used. The food locations were categorized into healthy dining $(7.4 \%)$, unhealthy dining $(14.8 \%)$, healthy fast food (7.4\%), unhealthy fast food (40.7\%), healthy café $(3.7 \%)$, unhealthy café $(18.5 \%)$, healthy prepackaged $(0 \%)$, and unhealthy prepackaged (7.4\%). Healthy eateries in total made up $18.5 \%$ and unhealthy eateries made up $81.4 \%$ of the food offerings (see Table 1).

Table 1. Results Eating establishment categories $(\mathrm{n}=27)$

\begin{tabular}{|c|c|c|c|c|c|c|c|c|}
\hline \multirow[t]{2}{*}{$\begin{array}{l}\text { Serving } \\
\text { Institution }\end{array}$} & \multicolumn{2}{|c|}{$\begin{array}{c}\text { Dining (sit down, full } \\
\text { table service, self service) }\end{array}$} & \multicolumn{2}{|c|}{$\begin{array}{c}\text { Fast food (minimal service, } \\
\text { quick preparation, food cooked } \\
\text { in bulk and reheated) }\end{array}$} & \multicolumn{2}{|c|}{$\begin{array}{c}\text { Café (primarily nonentree } \\
\text { items, coffee, pastries, } \\
\text { yogurt, smoothies) }\end{array}$} & \multicolumn{2}{|c|}{$\begin{array}{c}\text { Prepackaged (processed } \\
\text { snacks, prepackaged and paid } \\
\text { for at counter) }\end{array}$} \\
\hline & Healthy & Unhealthy & Healthy & Unhealthy & Healthy & Unhealthy & Healthy & Unhealthy \\
\hline $\begin{array}{c}\text { Institution } \\
\# 1\end{array}$ & 0 & 1 & 1 & 4 & 0 & 2 & 0 & 2 \\
\hline $\begin{array}{c}\text { Institution } \\
\quad \# 2\end{array}$ & 2 & 3 & 1 & 7 & 1 & 3 & 0 & 0 \\
\hline Total & $2(7.4 \%)$ & $4(14.8 \%)$ & $2(7.4 \%)$ & $11(40.7 \%)$ & $1(3.7 \%)$ & $5(18.5 \%)$ & $0(0 \%)$ & $2(7.4 \%)$ \\
\hline
\end{tabular}

\section{Discussion}

People learn to eat through a combination of biological, environmental, socioeconomic, and psychosocial factors. Dietary habits are developed and maintained based on these factors but are still malleable through education about future illness possibilities. A person's eating behaviors are built over one's life and changing habits must take into account financial ability, time available to prepare foods, cultural background, advertising, and more (Nestle et al., 1998). Family and cultural factors play a significant role in shaping a person's initial dietary habits. Food environments and accessibility contribute to what people eat, where they eat, and how much they eat (Cooksey-Stowers, Schwartz, \& Brownell, 2017).

Previous studies have even found evidence linking first year college residents to lower fruit, vegetable, and dairy consumption, as well as higher meat consumption (Pelletier \& Laska, 2012). Contributing to the weight gain seen in first-year students often are dining halls, vending machines, nearby restaurants, convenience stores, and other aspects of the campus food environment (Morrell, Lofgren, Burke, \& Reilly, 2012). Commuter students may also be resigned to utilizing the limited food options while on campus because of an inability to prepare meals in advance. Additionally, young adults are a population prone to consume fast food and thus victims of fast-food marketing. Consumption of this energy-dense, nutritionally-lacking foods results in poor dietary practices (Pelletier \& Laska, 2012).

College students are a population harshly impacted by the effects of food insecurity caused by the prevalence of food deserts and food swamps, leading to depressed academic, cognitive, and psychosocial development due to limited sources of nutrition necessary for one's wellbeing (Patton-López et al., 2014). Research has demonstrated that college can shape health behaviors. Therefore, these institutions are in a unique position to improve health behaviors and reduce health disparities.

Education and positive health behaviors are closely linked because an individual's behaviors can influence him in all aspects of life (Satia, 2010). Many food offerings at college campuses nurture unhealthy eating. Institutions are responsible for promoting healthy diets and wellbeing of their students but are lacking in their commitment to do so. A lack of proper nutrition can have detrimental effects on one's health. Post-secondary institutions have the ability to shape and nurture proper dietary habits in students. Therefore, it is important to take the steps needed to make improvements to the dietary offerings in order to reduce the negative health consequences for ethnic minority students at these institutions (Deshpande, M. Basil, \& D. Basil, 2009).

There were several limitations in this study. First, only two campuses in the same state were assessed and both are Hispanic serving institutions. Adding other types of minority serving institutions, such as Historically Black Colleges and Universities (HBCUs), to this study may have produced different results. Another limitation in this study was the lack of feedback from students regarding the actual food choices that they do make based on the 
establishments that they have access to. Finally, the link between dietary options and overall student health and health behaviors was not measured in this study.

\section{Conclusion}

Consumption of a nutritious, balanced diet is essential for good overall health. Racial and ethnic minority groups often experience diet-related disparities, leading to poor health and worse dietary behaviors in comparison to whites, but these disparities seem to stem from socioeconomic status (Satia, 2010). Income and socioeconomic status play a vital role in determining food-based disparities in minorities, with lower income individuals being closely associated with poor diet, decreased fruit and vegetable intake, and increased consumption of high fat food sources (Satia, 2010). Higher income households on average spend more money on both healthy and unhealthy foods from various sources, while financially struggling families; spend more money eating out (French, Walls, \& Mitchell, 2010). Additionally, the impact of neighborhood access in relation to environmental justice is an essential factor in food-based health disparities in minorities. Ethnic and racial minority groups, and low-income populations, face environmental challenges in their pursuit if nutritional and fulfilling food to promote healthy dietary choices. Due to the abundance of food deserts and food swamps, there is a disproportionate distribution of food sources that give rise to unhealthy long-term dietary behaviors (A. Hilmers, D. Hilmers, \& Save, 2012).

This study demonstrates that unhealthy food offerings at the chosen minority institutions far outweigh healthy food choices, promoting poor dietary habits among students. Even dining establishments that seemingly offer healthy dishes have more affordable, more appealing, and more plentiful unhealthy foods placed at the forefront of their business. Better nutrition offerings at educational institutions can improve students' dietary practices and be beneficial regarding health, intellectual development, and keep students from being malnourished, sedentary, or obese. Colleges can improve the eating habits of students by improving the nutritional value, cost, and convenience of the food that is available to the students. Through policy, curriculum for nutrition education, integration of nutrition education and school food service, training for school staff, community and family involvement, and program evaluation, institutions of higher education can better coordinate to promote healthier lifestyles for their students. Future studies should assess the food offerings at minority serving institutions throughout the United States. These studies should also focus on the connection between poor eating habits developed by students in minority serving institutions and worse health in years following graduation. On a larger scale, collaboration between food service providers and dietician will allow for better meal planning and preparation tactics at post-secondary institutions.

\section{References}

Carlson, A., \& Frazao, E. (2012). Carlson, A., \& Frazão, E. (2012). Are healthy foods really more expensive? It Depends on How You Measure the Price. USDA-ERS Economic Information Bulletin, (96). https://doi.org/10.2139/ssrn.2199553

Cavanaugh, E., Mallya, G., Brensinger, C., Tierney, A., \& Glanz, K. (2013). Nutrition Environments in Corner Stores in Philadelphia. Preventive Medicine, 56(2), 149-151. https://doi.org/10.1016/j.ypmed.2012.12.007

Centers for Disease Control and Prevention (CDC). (2014a). Strategies for reducing health disparities. Retrieved from https://www.cdc.gov/minorityhealth/chdir/strategies2014/Strategies2014.html

Centers for Disease Control and Prevention (CDC). (2014b). Health of Black or African-American Non-Hispanic population. Retrieved from http://www.cdc.gov/nchs/fastats/black-health.htm

Cooksey-Stowers, K., Schwartz, M. B., \& Brownell, K. D. (2017). Food Swamps Predict Obesity Rates Better Than Food Deserts in the United States. International Journal of Environmental Research and Public Health. https://doi.org/10.3390/ijerph14111366

Deshpande, S., Basil, M. D., \& Basil, D. Z. (2009). Factors Influencing Healthy Eating Habits Among College Students: An Application of the Health Belief Model. Health Marketing Quarterly, 26(2), 145-164. https://doi.org/10.1080/07359680802619834

Fleischhacker, S., Evenson, K., Rodriguez, D., \& Ammerman, A. (2011). A systematic review of fast food access studies. Obesity Review, 12, e460-e471. https://doi.org/10.1111/j.1467-789X.2010.00715.x

Giskes, K., van Lenthe, F., Avendano-Pabon, M., \& Brug, J. (2011). A systematic review of environmental factors and obesogenic dietary intake among adults: are we getting loser to understanding obesogenic environments? Obesity Review, 12, e95-e106. https://doi.org/10.1111/j.1467-789X.2010.00769.x

Glanz, K., Sallis J. F., Saelens, B. E., \& Frank, L. D. (2007). Nutrition Environment Measures Survey in Stores (NEMS-S): Development and evaluation. American Journal of Preventive Medicine, 32(4), 273-281. 
https://doi.org/10.1016/j.amepre.2006.12.019

Graham, G. (2005). Disparities in Cardiovascular Disease Risk in the United States. Current Cardiology Reviews, 11(3), 238-245. https://doi.org/10.2174/1573403X11666141122220003

Hilmers, A., Hilmers, D. C., \& Dave, J. (2012). Neighborhood disparities in access to healthy foods and their effects on environmental justice. American Journal of Public Health, 102(9), 1644-1654. https://doi.org/10.2105/AJPH.2012.300865

Hossain, P., Kawar, B., \& El Nahas, M. (2007). Obesity and diabetes in the developing world-a growing challenge. New England journal of medicine, 356(3), 213-215. https://doi.org/10.1056/NEJMp068177

Kapinos, K. A., \& Yakusheva, O. (2011). Environmental influences on young adult weight gain: Evidence from a natural experiment. Journal of Adolescent Health, 48, 52-58. https://doi.org/10.1016/j.jadohealth.2010.05.021

Kumanyika, S. (2018). K-9 Unraveling common threads in obesity risk among racial/ethnic minority and migrant populations. European Journal of Public Health, 28(1). https://doi.org/10.1093/eurpub/cky044.009

Laden, B. V. (2010). Hispanic-serving institutions: What are they? Where are they? Community College Journal of Research and Practice, 28(3), 181-198. https://doi.org/10.1080/10668920490256381

Merisotis, J. P., \& McCarthy, K. (2005). Retention and student success at minority-serving institutions. New Directions for Institutional Research, 125, 45-58. https://doi.org/10.1002/ir.138

Morrell, J. S., Lofgren, I. E., Burke, J. D., \& Reilly, R. A. (2012). Metabolic syndrome, obesity, and related risk factors among college men and women. Journal of American College Health, 60(1), 82-89. https://doi.org/10.1080/07448481.2011.582208

Nestle, M., Wing, R., Birch, L., DiSogra, L., Drewnowski, A., Middleton, S., ... Winston, M. (1998). Behavioral and Social Influences on Food Choice. Nutrition Reviews, 56, 50-74. https://doi.org/10.1111/j.1753-4887.1998.tb01732.x

Patton-López, M. M., López-Cevallos, D. F., Cancel-Tirado, D. I., \& Vazquez, L. (2014). Prevalence and Correlates of Food Insecurity Among Students Attending a Midsize Rural University in Oregon. Journal of Nutrition Education and Behavior, 46(3), 209-214. http://doi.org/10.1016/j.jneb.2013.10.007

Pelletier, J. E., \& Laska, M. N. (2013). Campus Food and Beverage Purchases are Associated with Indicators of Diet Quality in College Students Living off Campus. American Journal of Health Promotion, 28(2), 80-87. https://doi.org/10.4278/ajhp.120705-QUAN-326

Price, J. H., Khubchandani, J., McKinney, M., \& Braun, R. (2013). Racial/Ethnic Disparities in Chronic Diseases of Youths and Access to Health Care in the United States. Biomed Research Institution. https://doi.org/10.1155/2013/787616

Saelens, B. E., Glanz, K., Sallis J. F., \& Frank L. D. (2007). Nutrition Environment Measures Study in Restaurants (NEMS-R): Development and evaluation. American Journal of Preventive Medicine, 32(4), 282-289. https://doi.org/10.1016/j.amepre.2006.12.022

Satia, J. A. (2009). Diet-related disparities: Understanding the problem and accelerating solutions. Journal of the American Dietetic Association, 109(4), 610-615. https://doi.org/10.1016/j.jada.2008.12.019

\section{Copyrights}

Copyright for this article is retained by the author(s), with first publication rights granted to the journal.

This is an open-access article distributed under the terms and conditions of the Creative Commons Attribution license (http://creativecommons.org/licenses/by/4.0/). 